\title{
Failure Mode and Drift Control of MRF-CBF Dual Systems
}

\author{
Maria Teresa Giugliano, Alessandra Longo, Rosario Montuori and Vincenzo Piluso*
}

Department of Civil Engineering, University of Salerno, Italy

\begin{abstract}
In this paper, a new method for designing moment resisting frame (MRF) - concentrically braced frame (CBF) dual systems failing in global mode is presented. Starting from the analyses of the typical collapse mechanisms of such structural typology subjected to seismic horizontal forces, the method is based on the application of the kinematic theorem of plastic collapse. Beam and diagonal sections are assumed to be known quantities, because they are designed to resist vertical loads and horizontal forces, respectively. Therefore, the column sections are the only unknowns of the design problem. Column sections are obtained by imposing that the equilibrium curve corresponding to the global mechanism has to lie below all the equilibrium curves corresponding to the undesired collapse mechanisms within a displacement range compatible with the local ductility supply of dissipative elements. Such procedure has been applied to design several MRF-CBF dual systems and has been validated by means of non-linear static analyses aimed to check the actual pattern of yielding.
\end{abstract}

Keywords: Moment resisting frames - concentrically braced frames dual system, global mechanism, mechanism equilibrium curve, design methodology, non linear static analyses.

\section{INTRODUCTION}

The energy dissipation capacity of structures subjected to destructive seismic actions is strongly influenced by the kinematic mechanism developed at collapse. The need to prevent collapse mechanisms having limited dissipation capacity and to promote the development of a global failure mode is universally recognized. Significant research efforts have been spent in order to establish simple design criteria to avoid undesidered collapse mechanisms which undermine the global ductility supply and the energy dissipation capacity of structures. In particular, the problem of failure mode control is faced by modern seismic codes, among which Eurocode 8, by means of recommendations based on simple hierarchy criteria. The basic principles for designing seismicresistant dissipative structures, namely "capacity design" principles, state that non dissipative zones have to be designed in order to remain in elastic range and, therefore, they have to be proportioned on the basis of the maximum internal actions that dissipative zones are able to transmit. Conversely, dissipative zones have to be proportioned on the basis of the internal actions arising from seismic design load combinations prescribed by the codes. With reference to the most popular seismic resisting systems (i.e. moment resisting frames, eccentrically braced frames and concentrically braced frames) hierarchy criteria suggested by seismic codes constitute only a simplified application of capacity design principles, so that they do not lead to structures failing in global mode and, in some cases (particularly for braced frames) are not able to avoid the development of soft story mechanisms. Therefore, in order to design structures able to assure the development of a collapse mechanism of global type under destructive seismic actions, a rigorous application

\footnotetext{
*Address correspondence to this author at the Department of Civil Engineering, University of Salerno, Italy; Tel: $+39+089+964108$;

Fax: +39+089+964108; E-mail: v.piluso@unisa.it
}

of capacity design principles is needed, requiring more sophisticated design procedures. In particular, sophisticated design procedures assuring a collapse mechanism of global type have been already successfully developed with reference to moment-resisting frames (MRFs) [1, 2], concentrically braced frames (CBFs) [3, 4], eccentrically braced frames (EBFs) [5, 6] and knee braced frames (KBFs) [7].

Within the same framework, a new design procedure for MRF-CBF dual systems able to assure a global failure mode, is developed in this paper.

MRF-CBF dual systems constitute a reliable alternative for designers, as they combine the advantages of two basic structural typologies.

In fact, MRFs are characterized by high dissipation capacity, because of the large number of dissipative zones under cyclic bending represented by the beam end sections. Nevertheless, such structural system could be not able to provide sufficient lateral stiffness, as required to fulfill the serviceability limit state.

Conversely, CBFs provide the best solution regarding the limitation of the interstorey drift demand under seismic events having a return period comparable with the lifetime of the structure, because they provide the maximum lateral stiffness when compared with any other structural typology [8]. Nevertheless some uncertainty arises about the adequacy of such structures to assure collapse prevention under severe seismic actions by undergoing large excursions in the nonlinear range (i.e. the fulfilment of ultimate limit state), because they are penalized by the occurrence of the buckling of bracing members in compression which governs the shape of the hysteresis loops of such dissipative zones [9-12]. For this reason, MRF-CBF dual systems constitute a rational combination solution leading to a design able to satisfy both the ultimate limit state requirements and the serviceability limit state requirements. In fact, the exploitation of the dissipative 
capacity of beam ends and of the stiffness provided by diagonals allow to obtain high global ductility and limited interstorey drifts, so that both the ultimate and the serviceability limit state requirements can be easily satisfied. Notwithstanding, in order to obtain high global ductility, the need to control the location of dissipative zones, i.e. the control of the failure mode, is of primary importance. In this paper, with reference to MRF-CBF dual systems, a new design procedure aimed at the failure mode control is presented and applied.

A worked example aiming to show the practical application of the proposed design procedure, is also presented and, in addition, push-over analyses are carried out with reference to MRF-CBF dual systems, having different number of storeys, aiming to demonstrate the achievement of the design goal, i.e. the development of a collapse mechanism of global type. Therefore, the validation of the proposed design procedure is the outcome of the work.

\section{EQUILIBRIUM CURVES OF TYPICAL COLLAPSE MECHANISMS}

The proposed design procedure, aimed at the failure mode control, is based on the application of the kinematic theorem of plastic collapse. It starts from the observation that the collapse mechanism of dual systems under seismic horizontal forces can be considered as belonging to three main typologies (Fig. 1), where the collapse mechanism of global type is a particular case of type- 2 mechanism. The global mechanism is achieved when plastic hinges are developed at all the beam ends and at the base of first storey columns, while all the tensile diagonals are yielded and the compressed ones are in the buckled condition. The control of the failure mode can be performed by means of the analysis of $3 n_{s}$ mechanisms (being $n_{s}$ the number of storeys). The beam

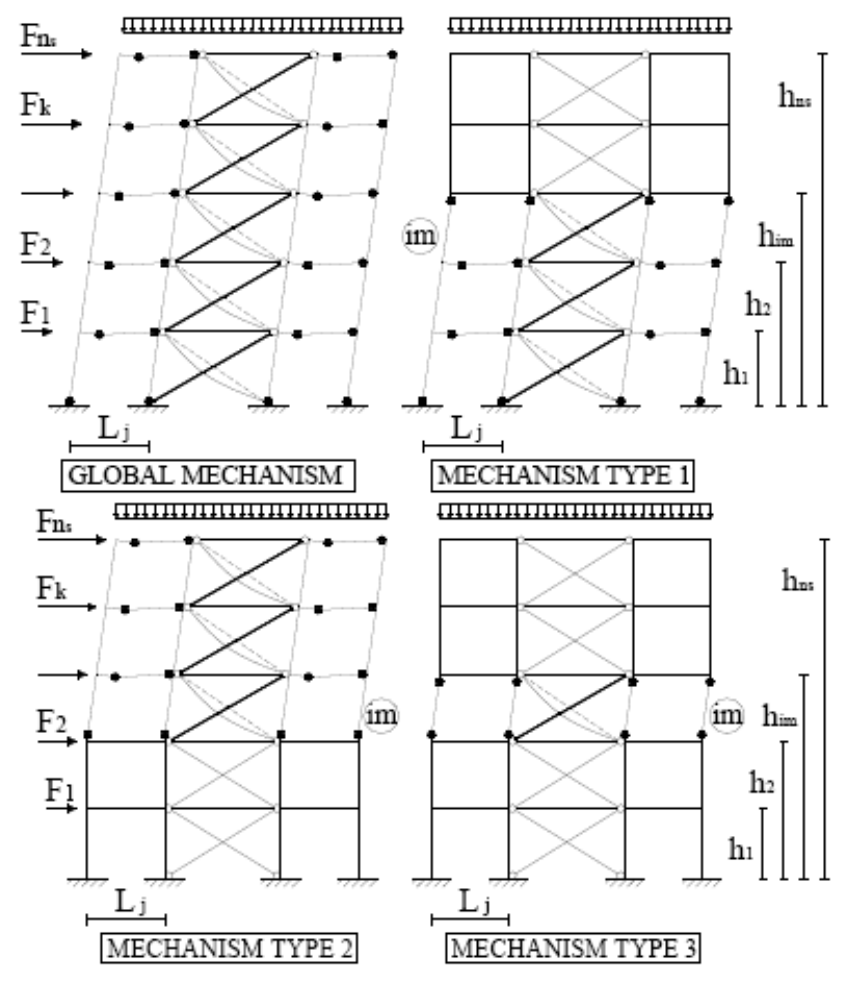

Fig. (1). Analysed collapse mechanism typologies. and diagonal sections are assumed to be known quantities as they are designed to withstand vertical loads and horizontal actions, respectively. The unknowns of the design problem are the column sections whose plastic modulus has to be defined so that the mechanism equilibrium curve $(\alpha-\delta)$ corresponding to the global mechanism has to lie below the equilibrium curves corresponding to all the other undesired mechanisms within a displacement range compatible with the local ductility supply of dissipative elements. This statement corresponds to the extension of the upper bound theorem to the concept of mechanism equilibrium curve [1, 2] and it allows to take into account also second order effects. Therefore, according to such kinematic approach, the global failure mode is the mechanism actually developed in the whole displacement range compatible with the local ductility supply. It means that the proposed design procedure allows in a single shot both the collapse mechanism control and the local ductility control.

The linearized mechanism equilibrium curve can be expressed as:

$$
\alpha_{c}=\alpha-\gamma \delta
$$

where $\alpha$ is the kinematically admissible multiplier of horizontal forces and $\gamma$ is the slope of the mechanism equilibrium curve.

The kinematically admissible multiplier of horizontal forces corresponding to the generic mechanism is obtained by means of the virtual work principle. For a virtual rotation $d \theta$ of the columns involved in the mechanism, the internal work is given by:

$$
W_{i}=\left[\operatorname{tr}\left(\mathbf{C}^{T} \mathbf{R}_{\mathbf{c}}\right)+2 \operatorname{tr}\left(\mathbf{B}^{T} \mathbf{R}_{\mathbf{b}}\right)+\operatorname{tr}\left(\mathbf{N}_{\mathbf{t}}^{\mathbf{T}} \mathbf{E}_{\mathbf{t}}\right)+\operatorname{tr}\left(\mathbf{N}_{\mathbf{c}}^{\mathbf{T}} \mathbf{E}_{\mathbf{c}}\right)\right] d \theta
$$

where:

- $t r$ denotes the trace of the matrix;

- $\mathbf{C}$ is a matrix of order $n_{c} \times n_{s}$ (number of columns $\times$ number of storeys) whose elements $C_{i k}$ are equal to the plastic moments of columns $\left(C_{i k}=M_{c, i k}\right)$;

- $\quad \mathbf{R}_{\mathbf{c}}$ is a matrix of order $n_{c} \times n_{s}$ whose elements, $R_{c, i k}$, are coefficients accounting for the participation of ith column of kth storey to the collapse mechanism. In particular, $R_{c, i k}=2$ when the column is yielded at both ends, $R_{c, i k}=1$ when only one column end is yielded and $R_{c, i k}=0$ when the column does not participate to the collapse mechanism;

- $\mathbf{B}$ is a matrix of order $n_{b} \times n_{s}$ (number of bays $\times$ number of storeys) whose elements $B_{j k}$ are equal to plastic moments of beams $\left(B_{j k}=M_{b, j k}\right)$;

- $\quad \mathbf{R}_{\mathbf{b}}$ is a matrix of order $n_{b} \times n_{s}$ whose elements, $R_{b, j k}$, are coefficients accounting for the participation of $\mathrm{j} t \mathrm{~h}$ beam of $\mathrm{k} t h$ storey to the collapse mechanism. In particular, $R_{b, j k}=0$ when the beam does not participate to the collapse mechanism (and for beams of braced bays if they are pin jointed to the columns), otherwise $R_{b, j k}=L_{j} /\left(L_{j}-x_{j k}\right)$, where $L_{j}$ is the span of $\mathrm{j} t h$ bay and $x_{j k}$ is the abscissa of second plastic hinge of $\mathrm{j}$ th beam of kth storey. This abscissa is given by $x_{j k}=L_{j}-2$. 
$\left(M_{b, j k} / q_{j k}\right)^{1 / 2}$ when the uniform vertical load $q_{j k}>4$. $M_{b, j k} / L_{j}^{2}$ and $x_{j k}=0$ in the opposite case [2];

- $\mathbf{N}_{\mathbf{t}}$ and $\mathbf{N}_{\mathbf{c}}$ are matrixes of order $n_{b r} \times n_{s}$ (number of braced bays $\times$ number of storeys) whose elements $N_{t, b k}$ and $N_{c, b k}$ are equal to the yield axial forces in tensile diagonals and the axial force accounting for the post-buckling behaviour of the compressed ones of $\mathrm{b} t h$ braced bay and $\mathrm{k}$ th storey, respectively, with reference to the collapse condition [3];

- $\mathbf{E}_{\mathbf{t}}$ and $\mathbf{E}_{\mathbf{c}}$ are matrixes of order $n_{b r} \times n_{s}$ whose elements, $e_{t, b k}$ and $e_{c, b k}$, are coefficients representing, respectively, the elongation of the tensile yielded diagonal and the shortening of the buckled compressed one belonging to the $\mathrm{b}$ th braced bay and $\mathrm{k} t h$ storey due to a unit rotation of columns. They are given by $l_{b k} \cos \alpha_{b k}$ ( $l_{b k}$ is the brace length) when the diagonal participates to the collapse mechanism, conversely $e_{t, b k}=e_{c, b k}=0$.

The external work due to horizontal forces and uniform loads acting on the beams, for a virtual rotation $d \theta$ of the columns involved in the mechanism, can be written as:

$$
\mathrm{W}_{\mathrm{e}}=\left[\alpha \cdot \mathbf{F}^{\mathrm{T}} \mathbf{s}+\operatorname{tr}\left(\mathbf{q}^{\mathrm{T}} \mathbf{D}_{\mathrm{v}}\right)\right] d \theta
$$

where:

- $\mathbf{F}$ is the vector of the design seismic horizontal forces equal to $\left\{F_{1}, F_{2}, \ldots \ldots ., F_{k}, \ldots \ldots, F_{n s}\right\}$, where $F_{k}$ is the horizontal force applied to the $\mathrm{k} t h$ storey;

- $\mathbf{s}$ is the shape vector of the storey horizontal virtual displacements (du $=\mathbf{s} \cdot d \theta$, where $d \theta$ is the virtual rotation of the plastic hinges of the columns involved in the mechanism);

- $\mathbf{q}$ is the matrix of order $n_{b} \times n_{s}$ (number of bays $\times$ number of storeys) of uniform vertical loads acting on the beams;

- $\mathbf{D}_{\mathbf{v}}$ is a matrix of order $n_{b} \times n_{s}$ whose elements, $D_{v, j k}$, are coefficients related to the external work of the uniform load acting on $\mathrm{j} t h$ beam of $\mathrm{k} t h$ storey. In particular $D_{v, j k}=L_{j} x_{j k} / 2$ when the beam participates to the collapse mechanism and $D_{v, j k}=0$ in the opposite case [2].

Therefore, the application of the virtual work principle provides the kinematically admissible multiplier:

$$
\alpha=\frac{\left[\operatorname{tr}\left(\mathbf{C}^{\mathrm{T}} \mathbf{R}_{\mathbf{c}}\right)+2 \operatorname{tr}\left(\mathbf{B}^{\mathrm{T}} \mathbf{R}_{\mathbf{b}}\right)+\operatorname{tr}\left(\mathbf{N}_{\mathbf{t}}^{\mathrm{T}} \mathbf{E}_{\mathbf{t}}\right)+\operatorname{tr}\left(\mathbf{N}_{\mathbf{c}}^{\mathrm{T}} \mathbf{E}_{\mathbf{c}}\right)-\operatorname{tr}\left(\mathbf{q}^{\mathrm{T}} \mathbf{D}_{\mathbf{v}}\right)\right]}{\mathbf{F}^{\mathrm{T}} \mathbf{S}}
$$

In order to evaluate the slope of the mechanism equilibrium curve, the second-order work due to vertical loads has to be evaluated. With reference to Fig. (2), it is possible to note that the horizontal displacement of the $\mathrm{k}$ th storey involved in the generic mechanism is given by $u_{k}=r_{k} \cdot \sin \theta$ where $r_{k}$ is the distance of the $\mathrm{k} t h$ storey from the centre of rotation $C$ and $\theta$ is the angle of rotation. In the same way, the top sway displacement is given by $\delta=H_{0} \cdot \sin \theta$, where $H_{0}$ is the sum of the interstorey heights of the storeys involved by the generic mechanism.

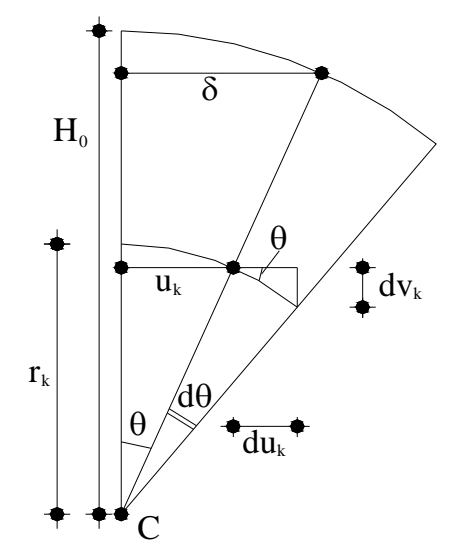

Fig. (2). Vertical virtual displacements due to second order effects.

In the case of infinitesimal values of $\theta$ rotation, it is possible to assume that $\tan \theta \approx \sin \theta$ and $\cos \theta \approx 1$, therefore the relationship between vertical and horizontal virtual displacements is $d v_{k}=d u_{k} \cdot \tan \theta \approx d u_{k} \cdot \sin \theta$.

As the ratio $d v_{k} / d u_{k}$ does not depend on the considered storey, it means that vertical and horizontal virtual displacement vectors have the same shape. In fact, the virtual horizontal displacements are given by $d u_{k}=r_{k} \cdot \cos \theta d \theta \approx r_{k} \cdot d \theta$, where $r_{k}$ defines the shape of the virtual horizontal displacement vector, while the virtual vertical displacements are given by $d v_{k}=\left(\delta / H_{0}\right) \cdot r_{k} \cdot d \theta$ and, therefore, they have the same shape $r_{k}$ of the horizontal ones. It can be concluded that $d v_{k}=\left(\delta / H_{0}\right) \cdot s \cdot d \theta$ and as a consequence, the second order work due to vertical loads is equal to:

$$
\mathrm{W}_{\mathrm{v}}=\mathbf{V}^{\mathrm{T}} \mathbf{s} \cdot \frac{\delta}{\mathrm{H}_{0}} d \theta
$$

where:

- $\mathbf{V}$ is the vector of the storey vertical loads $\left\{V_{l}, V_{2}, \ldots\right.$, $\left.V_{k}, \ldots, V_{n s}\right\}$, where $V_{k}$ is the total load acting at $\mathrm{k} t h$ storey.

Finally, the slope $\gamma$ of the equilibrium curve can be expressed as the ratio between the second order work due to vertical loads and the work due to horizontal forces:

$\gamma=\frac{\mathbf{V}^{\mathrm{T}} \mathbf{s}}{\mathbf{F}^{\mathrm{T}} \mathbf{s}} \cdot \frac{1}{\mathrm{H}_{0}}$

The following notation will be used to denote the parameters of the equilibrium curve of the considered mechanisms:

- $\alpha^{(\mathrm{g})}$ and $\gamma^{(\mathrm{g})}$ are, the kinematically admissible multiplier of the horizontal forces (rigid-plastic theory) and the slope of the softening branch of $\alpha-\delta$ curve, corresponding to the global-type mechanism;

- $\alpha_{i_{m}}^{(t)}$ and $\gamma^{(\mathrm{t})}$ im have the same meaning of the previous symbols, but they refers to the $\mathrm{i}_{\mathrm{m}}$ th mechanism (Fig. 1) of the $t$ th type $(t=1,2,3)$.

The expressions of the above parameters will be furtherly developed in order to point out the contribution of the columns to the internal work. 


\subsection{Global Type Mechanism}

In the case of global type mechanism (Fig. 1), the shape vector of the horizontal displacements is given by:

$\mathbf{s}^{(g)}=\mathbf{h}=\left\{h_{1}, h_{2}, \ldots, h_{n_{s}}\right\}^{T}$

As all the storeys are involved in the mechanism, all the beam ends and the tensile diagonals are yielded and all the compressed ones are in the bucked condition. This structural behaviour is taken into account through the matrixes $\mathbf{R}_{\mathbf{b}}^{(\mathbf{g})}$ related to the plastic rotation of beam ends, $\mathbf{N}_{t}^{\mathbf{T}}$ and $\mathbf{N}_{\mathbf{c}}^{\mathbf{T}}$ related to the lengthening and shortening of tensile and compressed diagonals, respectively. Therefore, the kinematically admissible multiplier is given by:

$\alpha^{(g)}=\frac{\left[\mathbf{M}_{\mathbf{c} 1}^{\mathrm{T}} \mathbf{I}+2 \operatorname{tr}\left(\mathbf{B}^{\mathrm{T}} \mathbf{R}_{\mathbf{b}}^{(\mathrm{g})}\right)+\operatorname{tr}\left(\mathbf{N}_{\mathbf{t}}^{\mathrm{T}} \mathbf{E}_{\mathbf{t}}^{(\mathbf{g})}\right)+\operatorname{tr}\left(\mathbf{N}_{\mathbf{c}}^{\mathrm{T}} \mathbf{E}_{\mathbf{c}}^{(\mathbf{g})}\right)\right]-\operatorname{tr}\left(\mathbf{q}^{\mathrm{T}} \mathbf{D}_{\mathbf{v}}^{(\mathrm{g})}\right)}{\mathbf{F}^{\mathrm{T}} \mathbf{s}^{(\mathbf{g})}}$

where $\mathbf{I}$ is the unit vector of order $\mathrm{n}_{\mathrm{c}}$. In addition, taking into account that the coefficient $H_{0}$ is equal to $h_{n s}$, because all the storeys are involved in the collapse mechanism, the slope $\gamma^{(g)}$ of the equilibrium curve is obtained by means of Eq. (6):

$\gamma^{(g)}=\frac{\mathbf{V}^{\mathbf{T}} \mathbf{s}^{(\mathbf{g})}}{\mathbf{F}^{\mathbf{T}} \mathbf{s}^{\mathbf{( g )}}} \cdot \frac{1}{\mathrm{~h}_{\mathrm{ns}}}$

\subsection{Type-1 Mechanism}

With reference to the $i_{m}$ th mechanism of type- 1 , the shape vector of horizontal displacements is expressed as:

$\mathbf{s}_{i_{m}}^{(1)}=\left\{h_{1}, h_{2}, \ldots, h_{i_{m}}, h_{i_{m}}, h_{i_{m}}\right\}^{T}$

where the first element equal to $h_{i m}$ corresponds to the $\mathrm{i}_{\mathrm{m}} t h$ component.

In this case, only the beams and the diagonals of the first $\mathrm{i}_{\mathrm{m}}$ storeys are involved in the mechanism, whereas plastic hinges in columns develop at the base of the first storey and at the top of the $\mathrm{i}_{\mathrm{m}}$ th storey, so that the following relationship is obtained:

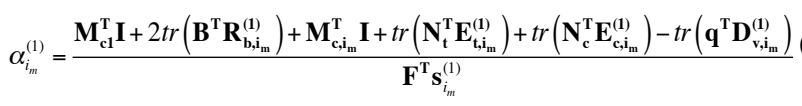

The slope of the mechanism equilibrium curve is obtained from Eq. (6) with $\mathrm{H}_{0}=\mathrm{h}_{\mathrm{im}}$ and $\mathbf{s}=\mathbf{s}_{\mathbf{i m}}{ }^{\text {(1) }}$.

$\gamma_{i_{m}}^{(1)}=\frac{\mathbf{V}^{\mathrm{T}} \mathbf{s}_{i m}{ }^{(1)}}{\mathbf{F}^{\mathbf{T}} \mathbf{s}_{i m}{ }^{(1)}} \cdot \frac{1}{\mathrm{~h}_{\mathrm{im}}}$

\subsection{Type 2 Mechanism}

Regarding the $\mathrm{i}_{\mathrm{m}}$ th mechanism of type 2 (Fig. 1), the shape vector of horizontal displacements can be written as:

$\mathbf{s}_{\mathbf{i}_{\mathrm{m}}}^{(\mathbf{2})}=\left\{0,0,0,0, h_{i_{m}}-h_{i_{m}-1}, h_{i_{m}+1}-h_{i_{m}-1}, \ldots, h_{n_{s}}-h_{i_{m}-1}\right\}^{T}$

where the first non-zero element of the above vector is the $\mathrm{i}_{\mathrm{m}}$ th one.

The kinematically ammissible multiplier corresponding to type-2 mechanism is given by:

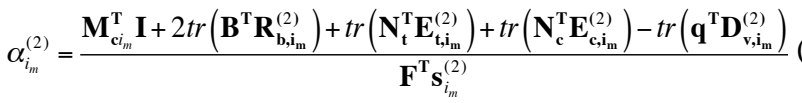

In addition, the $\mathrm{i}_{\mathrm{m}}$ th storey and those above it participate to the mechanism, so that the slope of the mechanism equilibrium curve is obtained from Eq. (6) with $\mathrm{H}_{0}=\mathrm{h}_{\mathrm{ns}}-\mathrm{h}_{\mathrm{im}-1}$ and $\mathbf{S}=\mathbf{S}_{\mathbf{i}_{\mathrm{m}}}^{(2)}$

$\gamma_{i_{m}}^{(2)}=\frac{\mathbf{V}^{\mathbf{T}} \mathbf{s}_{i m}{ }^{(2)}}{\mathbf{F}^{\mathbf{T}} \mathbf{s}_{i m}{ }^{(2)}} \cdot \frac{1}{\mathrm{~h}_{\mathrm{ns}}-\mathrm{h}_{\mathrm{i}_{\mathrm{m}}-1}}$

\subsection{Type-3 Mechanism}

Finally, with reference to the $i_{m}$ th mechanism of type 3 (Fig. 1) the shape vector of horizontal displacements can be written as:

$\mathbf{s}_{\mathbf{i}_{\mathrm{m}}}^{(\mathbf{3})}=\left(h_{i_{m}}-h_{i_{m}-1}\right)\{0,0, \ldots, 0,1,1,1, \ldots \ldots . .1\}^{T}$

where the first term different from zero is the $i_{m}$ th one.

Therefore, the kinematically admissible multiplier of the $\mathrm{i}_{\mathrm{m}}$ th mechanism of type- 3 is given by:

$\alpha_{i_{m}}^{(3)}=\frac{2 \mathbf{M}_{\mathbf{c}_{i}}^{\mathbf{T}} \mathbf{I}+\operatorname{tr}\left(\mathbf{N}_{\mathbf{t}}^{\mathbf{T}} \mathbf{E}_{\mathbf{t}, \mathbf{i}_{\mathbf{m}}}^{(3)}\right)+\operatorname{tr}\left(\mathbf{N}_{\mathbf{c}}^{\mathbf{T}} \mathbf{E}_{\mathbf{c}, \mathbf{i}_{\mathbf{m}}}^{(3)}\right)}{\mathbf{F}^{\mathrm{T}} \mathbf{s}_{i_{m}}^{(3)}}$

which takes into account that only the columns and the tensile and compressed diagonals of $i_{m}$ th storey are involved in the mechanism.

The slope of the mechanism equilibrium curve is obtained from Eq. (6) with $\mathrm{H}_{0}=\mathrm{h}_{\mathrm{im}}-\mathrm{h}_{\mathrm{im}-1}$ and $\mathbf{s}=\mathbf{s}_{\mathbf{i}_{\mathrm{m}}}^{(\mathbf{3})}$ :

$\gamma_{i_{m}}^{(3)}=\frac{\mathbf{V}^{\mathrm{T}} \mathbf{s}_{i m}{ }^{(3)}}{\mathbf{F}^{\mathrm{T}} \mathbf{s}_{i m}{ }^{(3)}} \cdot \frac{1}{\mathrm{~h}_{\mathrm{i}_{\mathrm{m}}}-\mathrm{h}_{\mathrm{i}_{\mathrm{m}}-1}}$

\section{DESIGN CONDITIONS FOR FAILURE MODE CONTROL}

The design of structures able to fail in global mode requires that cross-sections of columns are dimensioned to assure that, according to the upper bound theorem of plastic collapse, the kinematically admissible horizontal force multiplier corresponding to the global mechanism is the minimum among all the kinematically admissible multipliers. This condition is necessary, but not sufficient in the case of elastoplastic behaviour of structural material. In fact, the structure exhibits large displacements before collapse and, as a consequence, second order effects cannot be neglected in the design process. Therefore, the design conditions have to be defined by imposing, as shown in Fig. (3), that the equilibrium curve corresponding to the global type mechanism has to lie below those corresponding to all the other undesired mechanisms within a displacement range compatible with the plastic deformation capacity of members. Therefore, the design conditions are expressed by means of the following relationships:

$$
\begin{aligned}
& \alpha^{(g)}-\gamma^{(g)} \cdot \delta_{u} \leq \alpha_{i m}^{(t)}-\gamma_{i m}^{(t)} \cdot \delta_{u} \quad \text { with } \\
& \mathrm{i}_{\mathrm{m}}=1,2, . . n_{s} \text { and } \mathrm{t}=1,2,3
\end{aligned}
$$




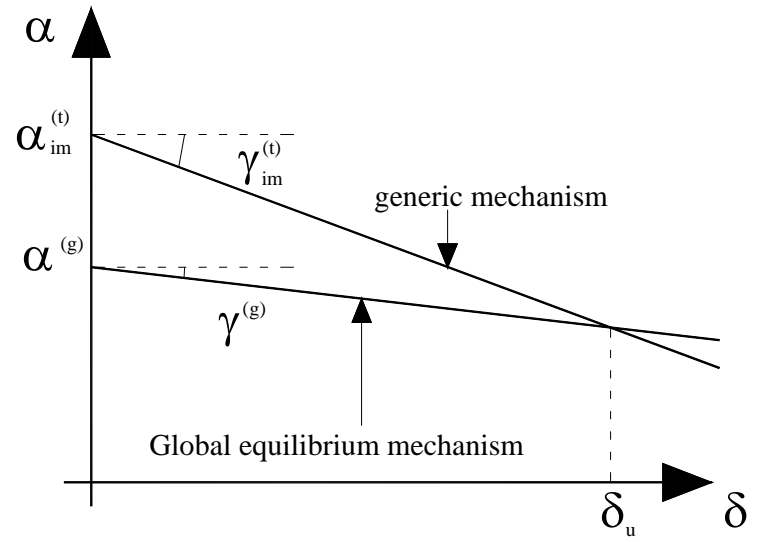

Fig. (3). Design conditions.

Substituting the expressions of $\alpha^{(\mathrm{g})}, \gamma^{(\mathrm{g})}$ and $\alpha_{i m}^{(t)}, \gamma_{i m}^{(t)}$ in equations (19), the design conditions to be satisfied in order to avoid the undesired mechanisms are obtained, where the unknowns are the plastic moments of columns, reduced due to the contemporary action of axial forces, which can be obtained by means of an appropriate numerical algorithm [2, $13,14]$.

For sake of synthesis, the development relationships (19) will be herein reported in the case of type- 1 mechanisms only. The $n_{s}$ conditions to avoid type- 1 mechanisms $(t=1)$ can be expressed as:

$$
\frac{\left[\mathbf{M}_{\mathrm{c} 1}^{\mathrm{T}} \cdot \mathbf{I}+2 \operatorname{tr}\left(\mathbf{B}^{\mathrm{T}} \cdot \mathbf{R}_{\mathrm{b}}^{(\mathrm{g})}\right)+\operatorname{tr}\left(\mathbf{N}_{\mathrm{t}}^{\mathrm{T}} \cdot \mathbf{E}_{\mathrm{t}}^{(\mathrm{g})}\right)+\operatorname{tr}\left(\mathbf{N}_{\mathrm{c}}^{\mathrm{T}} \cdot \mathbf{E}_{\mathrm{c}}^{(\mathrm{g})}\right)-\operatorname{tr}\left(\mathbf{q}^{\mathrm{T}} \cdot \mathbf{D}_{\mathrm{v}}^{(\mathrm{g})}\right)-\mathbf{V}^{\mathrm{T}} \mathbf{s}^{(\mathrm{g})} \frac{\delta_{\mathrm{u}}}{\mathrm{h}_{\mathrm{ns}}}\right]}{\mathbf{F}^{T} \cdot \mathbf{s}^{(\mathrm{g})}} \leq
$$

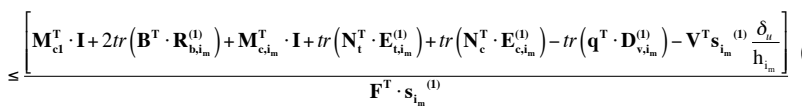

In order to arrange the above design conditions in a convenient form, it is useful to introduce the following parameters making reference to the global mechanism:

$$
\begin{aligned}
& \mu^{(g)}=2 \operatorname{tr}\left(\mathbf{B}^{\mathbf{T}} \cdot \mathbf{R}_{\mathbf{b}}^{(\mathbf{g})}\right)=2 \sum_{k=1}^{n s} \sum_{j=1}^{n b} M_{b, j k} \cdot R_{b, j k} \\
& \boldsymbol{v}^{(g)}=\frac{1}{h_{n s}} \cdot \mathbf{V}^{\mathbf{T}} \cdot \mathbf{s}^{(\mathbf{g})}=\sum_{k=1}^{n s} V_{k} \cdot h_{k} \cdot \frac{1}{h_{n s}} \\
& \boldsymbol{\tau}^{(g)}=\operatorname{tr}\left(\mathbf{q}^{\mathbf{T}} \cdot \mathbf{D}_{\mathbf{v}}^{(\mathbf{g})}\right)=\sum_{k=1}^{n s} \sum_{j=1}^{n b} q_{j k} \cdot D_{v, j k} \\
& \omega^{(g)}=\operatorname{tr}\left(\mathbf{N}_{t} \cdot \mathbf{E}_{t}^{(\mathbf{g})}\right)+\operatorname{tr}\left(\mathbf{N}_{\mathbf{c}} \cdot \mathbf{E}_{\mathbf{c}}^{(\mathbf{g})}\right)=\sum_{k=1}^{n s} \sum_{b=1}^{n b r} N_{c, b k} \cdot l_{b k} \\
& \cdot \cos \alpha_{b k}+\sum_{k=1}^{n s} \sum_{b=1}^{n b r} N_{t, b k} \cdot l_{b k} \cdot \cos \alpha_{b k}
\end{aligned}
$$

where the parameter $\mu^{(\mathrm{g})}$ represents the internal work developed by beams, the parameter $v^{(\mathrm{g})}$ is related to the secondorder work due to vertical loads, the parameter $\tau^{(\mathrm{g})}$ represents the external work due to the uniform vertical loads acting on the beams, while $\omega^{(\mathrm{g})}$ represents the internal work associate to the lengthening and shortening of bracing members. All these parameters are known quantities, because both the plastic resistance of dissipative members (plastic moment of beams, axial resistance of tensile diagonals and postbuckling resistance of compressed ones) and the magnitude of vertical loads are data of the design problem.

In addition, the following non dimensional functions related to the $\mathrm{i}_{\mathrm{m}}$ th mechanism of type- 1 can be defined:

$$
\begin{aligned}
& \xi_{i_{m}}=\frac{2 \operatorname{tr}\left(\mathbf{B}^{\mathbf{T}} \cdot \mathbf{R}_{\mathbf{b}, \mathbf{i}_{\mathbf{m}}}^{(\mathbf{1})}\right)}{2 \operatorname{tr}\left(\mathbf{B}^{\mathbf{T}} \cdot \mathbf{R}_{\mathbf{b}}^{(\mathbf{g})}\right)}=\frac{2 \operatorname{tr}\left(\mathbf{B}^{\mathbf{T}} \cdot \mathbf{R}_{\mathbf{b}, \mathbf{i}_{\mathbf{m}}}^{(\mathbf{1})}\right)}{\mu^{(g)}}= \\
& \frac{2 \sum_{k=1}^{i_{m}-1} \sum_{j=1}^{n_{b}} M_{b, j k} \cdot R_{b, j k}}{\mu^{(g)}}
\end{aligned}
$$

$\lambda_{i_{m}}=\frac{\mathbf{F}^{\mathbf{T}} \cdot \mathbf{s}_{\mathbf{i}_{\mathbf{m}}}^{\mathbf{1})}}{\mathbf{F}^{\mathbf{T}} \cdot \mathbf{s}^{(\mathbf{g})}}=\frac{\sum_{k=1}^{i_{m}} F_{k} \cdot h_{k}+h_{i_{m}} \sum_{k=i_{m}+1}^{n_{s}} F_{k}}{\sum_{k=1}^{n_{s}} F_{k} \cdot h_{k}}$

$$
\begin{aligned}
& \varsigma_{i_{m}}^{(1)}=\frac{\operatorname{tr}\left(\mathbf{q}^{\mathbf{T}} \cdot \mathbf{D}_{\mathbf{v}, \mathbf{i}_{\mathbf{m}}}^{(\mathbf{1})}\right)}{\operatorname{tr}\left(\mathbf{q}^{\mathbf{T}} \cdot \mathbf{D}_{\mathbf{v}}^{(\mathbf{g})}\right)}=\frac{\operatorname{tr}\left(\mathbf{q}^{\mathbf{T}} \cdot \mathbf{D}_{\mathbf{v}, \mathbf{i}_{\mathbf{m}}}^{(\mathbf{1})}\right)}{\boldsymbol{\tau}^{(g)}}=\frac{\sum_{k=1}^{i_{m}-1} \sum_{j=1}^{n_{b}} q_{j k} \cdot D_{v, j k}}{\tau^{(g)}} \\
& \eta_{i_{m}}^{(1)}=\frac{\operatorname{tr}\left(\mathbf{N}_{\mathbf{t}} \cdot \mathbf{E}_{\mathbf{t}, \mathbf{i}_{\mathbf{m}}}^{(\mathbf{1})}\right)+\operatorname{tr}\left(\mathbf{N}_{\mathbf{c}} \cdot \mathbf{E}_{\mathbf{c}, \mathbf{i}_{\mathbf{m}}}^{(\mathbf{1})}\right)}{\operatorname{tr}\left(\mathbf{N}_{\mathbf{t}} \cdot \mathbf{E}_{\mathbf{t}}^{(\mathbf{g})}\right)+\operatorname{tr}\left(\mathbf{N}_{\mathbf{c}} \cdot \mathbf{E}_{\mathbf{c}}^{(\mathbf{g})}\right)}=\frac{\operatorname{tr}\left(\mathbf{N}_{\mathbf{t}} \cdot \mathbf{E}_{\mathbf{t}, \mathbf{i}_{\mathbf{m}}}^{(\mathbf{1})}\right)+\operatorname{tr}\left(\mathbf{N}_{\mathbf{c}} \cdot \mathbf{E}_{\mathbf{c}, \mathbf{i}_{\mathbf{m}}}^{(\mathbf{1})}\right)}{\omega^{(g)}}= \\
& =\frac{\sum_{k=1}^{i_{m}} \sum_{b=1}^{n_{b r}} N_{c, b k} \cdot l_{b k} \cdot \cos \alpha_{b k}+\sum_{k=1}^{i_{m}} \sum_{b=1}^{n_{b r}} N_{t, b k} \cdot l_{b k} \cdot \cos \alpha_{b k}}{\omega^{(g)}}
\end{aligned}
$$

where the function $\xi_{\text {im }}$ represents the ratio between the work developed by the beams in the $\mathrm{i}_{\mathrm{m}}$ th mechanisms of type- 1 and that developed in the global mechanisms. The functions $\lambda_{\text {im }}$ represents the ratio between the external work which the horizontal forces develop in mechanisms of type- 1 and that developed in the global mechanism. The function $\zeta_{i_{m}}^{(1)}$ is the ratio between the external work which the uniform vertical loads develop in mechanisms of type- 1 and that developed in the global mechanism. Finally, the function $\eta_{\mathbf{i}_{\mathrm{m}}}^{(1)}$ represents the ratio between the internal work developed, in the $i_{m}$ th mechanisms of type-1, by the bracing members and the same work developed in the global mechanism. As a consequence of the definition of the above parameters, the function $\xi_{\mathrm{im}}$ is known because the beam sections are designed accounting for to the magnitude of uniform vertical loads $\left(\mathrm{q}_{\mathrm{jk}}\right)$. In addition, because the uniform vertical loads $\left(\mathrm{q}_{\mathrm{jk}}\right)$ and the seismic horizontal forces $\left(\mathrm{F}_{\mathrm{k}}\right)$ are known, the functions $\lambda_{\mathbf{i}_{\mathbf{m}}}$ and $\zeta_{\mathbf{i}_{\mathrm{m}}}^{(1)}$ are also known. Finally, as the diagonal sections are designed accounting for the seismic horizontal forces, the function $\eta_{i_{\mathrm{m}}}^{(1)}$ is also known.

In order to account for the second order effects, an additional non dimensional function can be defined as the ratio between the slope of the equilibrium curve of the $i_{m}$ th mechanism of type- 1 and that corresponding to the global mechanism: 


$$
\begin{aligned}
& \Delta_{i_{m}}^{(1)}=\frac{\mathbf{F}^{\mathbf{T}} \cdot \mathbf{s}^{(\mathbf{g})}}{\mathbf{F}^{\mathbf{T}} \cdot \mathbf{s}_{\mathbf{i}_{\mathbf{m}}}^{(\mathbf{1})}} \cdot \frac{\frac{1}{h_{i_{m}}} \cdot \mathbf{V}^{\mathbf{T}} \cdot \mathbf{s}_{\mathbf{i}_{\mathbf{m}}}^{(\mathbf{1})}}{\frac{1}{h_{n s}} \cdot \mathbf{V}^{\mathbf{T}} \cdot \mathbf{s}^{(\mathbf{g})}}=\frac{1}{\lambda_{i_{m}}} \cdot \frac{\frac{1}{h_{i_{m}}} \cdot \mathbf{V}^{\mathbf{T}} \cdot \mathbf{s}_{\mathbf{i}_{\mathbf{m}}}^{(\mathbf{1})}}{\boldsymbol{v}^{(g)}}= \\
& \frac{\frac{1}{\lambda_{i_{m}}} \cdot\left(\sum_{k=1}^{i_{m}} V_{k} \cdot h_{k}+h_{i_{m}} \sum_{k=i_{m}+1}^{n_{s}} V_{k}\right) \cdot \frac{1}{h_{i_{m}}}}{\boldsymbol{v}^{(g)}}
\end{aligned}
$$

The $n_{s}$ design conditions expressed by equation (20) for $\mathrm{t}=1$ can be re-arranged by introducing the above defined parameters:

$$
\begin{aligned}
& \mathbf{M}_{\mathbf{c}, \mathbf{1}}^{\mathbf{T}} \cdot \mathbf{I} \cdot\left(1-\frac{1}{\lambda_{i_{m}}}\right)+\mu^{(g)}\left(1-\frac{\xi_{i_{m}}}{\lambda_{i_{m}}}\right)+\tau^{(g)}\left(\frac{\zeta_{i_{m}}^{(1)}}{\lambda_{i_{m}}}-1\right)+ \\
& \omega^{(g)}\left(1-\frac{\eta_{i_{m}}^{(1)}}{\lambda_{i_{m}}}\right)+v^{(g)}\left(\Delta_{i m}^{(1)}-1\right) \delta_{u} \leq \frac{1}{\lambda_{i_{m}}} \cdot \mathbf{M}_{\mathbf{c}, \mathbf{i}_{\mathrm{m}}}^{\mathbf{T}} \cdot \mathbf{I}
\end{aligned}
$$

In addition, it is convenient to define another parameter as the ratio between the sum of the reduced plastic moments of the $\mathrm{i}_{\mathrm{m}}$ th storey columns and the same sum referred to the first storey columns:

$$
\rho_{i_{m}}=\frac{\mathbf{M}_{\mathbf{c}, \mathbf{i}_{\mathbf{m}}}^{\mathbf{T}} \cdot \mathbf{I}}{\mathbf{M}_{\mathbf{c}, \mathbf{1}}^{\mathbf{T}} \cdot \mathbf{I}}=\frac{\sum_{i=1}^{n_{c}} M_{c, i i_{m}}}{\sum_{i=1}^{n_{c}} M_{c, i 1}}
$$

Denoting by $\rho_{i_{m}}^{(1)}$ the values of the above ratios which have to be assured to prevent failure according to type-1 collapse mechanisms, the $\mathrm{i}_{\mathrm{m}}$ th condition to be satisfied to avoid these collapse mechanisms can be written in the following form:

$$
\rho_{i_{m}}^{(1)} \geq \frac{\sum_{i=1}^{n_{s}} M_{c, i 1}\left(1-\frac{1}{\lambda_{i_{m}}}\right)+\mu^{(g)}\left(1-\frac{\xi_{i_{m}}}{\lambda_{i_{m}}}\right)+\tau^{(g)}\left(\frac{\xi_{i_{m}}^{(1)}}{\lambda_{i_{m}}}-1\right)+\omega^{(g)}\left(1-\frac{\eta_{i_{m}}^{(1)}}{\lambda_{i_{m}}}\right)+v^{(g)}\left(\Delta_{i_{m}}^{(1)}-1\right) \delta_{u}}{\frac{1}{\lambda_{i_{m}}} \sum_{i=1}^{n_{i}} M_{c, i 1}}
$$

The design conditions to avoid type- 2 and type- 3 mechanisms can be analogously derived starting from Eq. (19), for $\mathrm{t}=2$ and $\mathrm{t}=3$, respectively, and accounting for Eqs. (8-9), (1415) and (16-17).

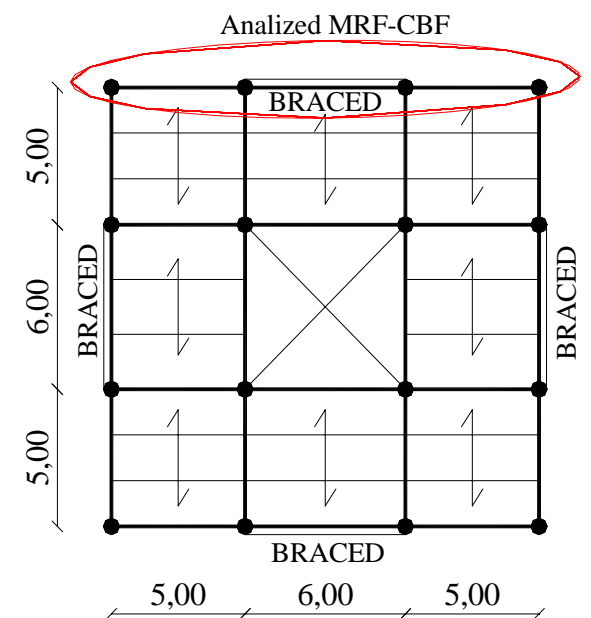

(a)
Therefore, the application of the presented design procedure allows the definition of the column plastic moments, reduced due to the contemporary presence of the axial force, by evaluating the $\rho_{i_{m}}$ values required at any storey. The knowledge of $\rho_{i_{m}}$ parameters allows the evaluation at any storey of the sum of the require plastic moments $\left(\sum_{i=1}^{n_{c}} M_{c . i_{i m}}\right)$ which can be properly distributed among the different columns of the $\mathrm{i}_{\mathrm{m}}$ th storey.

As a consequence, the final step of the proposed procedure, consists in evaluating the axial forces occurring in the columns in the collapse condition. This step can be easily carried out accounting for the shear forces transmitted by beams and the vertical components of the axial forces in yielded tensile diagonals and buckled compressed diagonals. In particular, with reference to the external and internal columns of the analysed structural configuration (Fig. 4b), the shear forces transmitted by the beams and diagonals, are given by:

$$
\begin{aligned}
& S=\frac{q \cdot L}{2} \mp \frac{2 M_{b}}{L} \text { (External columns) } \\
& S=\frac{q \cdot L}{2} \pm \frac{2 M_{b}}{L} \mp\left(N_{c}+N_{t}\right) \cdot \operatorname{sen} \alpha \text { (Internal columns) }
\end{aligned}
$$

where $M_{b}$ represents the plastic moment of beams, $N_{c}$ and $N_{t}$ the axial resistance in compression and in tension, respectively, of diagonal members. In addition, the first combination sign of the above equations refers to the left column while the second one to the right column.

Furthermore, it is useful to underline that Eq. (33) and (34) are valid provided that the uniform load satisfies the limitation $q \leq 4 M_{b} / L^{2}$, otherwise they have to be properly modified accounting for the influence of $q$ on the location of the second plastic hinge in the beam [1].

The algorithm to compute the column sections to be adopted to satisfy the design requirements described above has been codified into a computer program namely, SOPDODS (Second Order Plastic Design of Dual Systems). For sake of simplicity, aiming to investigate the consequences of

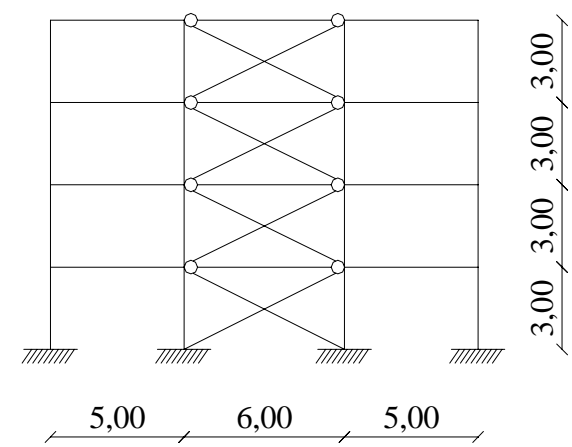

(b)

Fig. (4). a) Plan configuration of analysed buildings; b) structural configuration of MRF-CBF dual systems. 
the additional design requirements related to serviceability, only the application of the described design procedure is herein presented. A detailed discussion of the design procedure, with a developed numerical example, is given in [2] with reference to moment-resisting frames. The presentation of a completely developed numerical example dealing with dual systems is herein omitted, being the subject of a forthcoming work.

Regarding the possible limitations of the proposed design procedure, they can be related to the assumption of a vertical distribution of horizontal forces according to the first mode of vibration, so that discussions could arise concerning the influence of higher modes of vibrations, similarly to the case of the classical push-over analyses. However, even though the influence of higher modes of vibrations can be accounted for by means of an iterative design procedure based on repeated second order plastic analyses where the horizontal force distribution is changed according to an appropriate combination of the required number of vibration modes corresponding to the structure resulting from the previous design step, this is usually not needed. In fact, according to the experience cumulated by the authors in the problem of failure mode control of structures and to the results coming from incremental dynamic non linear analyses, structures whose failure mode is developing towards the global collapse mechanism exhibit a non linear behaviour which can be accurately predicted by means of either push-over analyses or plastic analyses based on a distribution of horizontal forces according to the first mode of vibration. This statement is also testified by the fact that, when the collapse mechanism is completely developed, the corresponding shape vector of horizontal displacement is actually triangular. Conversely, this is not the case of structures developing a partial collapse mechanism or even a soft storey mechanism where the shape vector of horizontal displacements is significantly far from the triangular distribution, so that in these cases higher modes of vibration become more and more important as the structure evolves significantly in plastic range.

\section{APPLICATIONS}

In order to check the accuracy of the proposed design methodology aimed at the failure mode control of MRF-CBF dual systems three structures with different number of storeys have been designed, and their inelastic behaviour has been investigated by means of push-over analyses carried out using SAP 2000 computer program [15].

The analysed structures are characterised by a regular plan configuration as depicted in Fig. (4a). MRF-CBF dual systems, located along the perimeter of the structure, constitute the only lateral load resisting systems as beam-tocolumn connections of internal elements are assumed to be pinned. The values of dead and live loads are, respectively, equal to $4 \mathrm{kN} / \mathrm{m}^{2}$ and $2 \mathrm{kN} / \mathrm{m}^{2}$. The steel grade is $\mathrm{S} 275$, so that the value of the yield stress is $f_{y}=275 \mathrm{MPa}$. In Fig. (4b) the structural configuration of the analysed MRF-CBF dual systems is also depicted with reference to a 4-storeys building: the central X-braced bay and the two external unbraced bays have span lengths equal to $6.0 \mathrm{~m}$ and $5.0 \mathrm{~m}$, respectively, and the interstorey height is equal to $3.0 \mathrm{~m}$. Beams of braced bays and diagonals are pin-jointed to the columns.
Three different structures have been analysed having, respectively, 4, 6 and 8 storeys.

The analysed MRF-CBF dual systems have been designed by means of the application of the proposed design methodology aimed at the failure mode control. According to such procedure, beams and diagonals are designed to resist, respectively, vertical and horizontal loads. In particular, the diagonals have been dimensioned to withstand the whole design seismic actions computed by means of the application of Eurocode 8 provisions [16], assuming a peak ground acceleration equal to $0.35 \mathrm{~g}$, a seismic response factor equal to 2.5 , soil type $\mathrm{A}$ and behaviour factor $\mathrm{q}$ equal to 4 , i.e. the $\mathrm{q}$ factor of CBFs. In addition, diagonals have been designed to fulfill the brace slenderness limitation provided by Eurocode 8 for CBFs [16]; therefore bracing members are able to provide both an increase in lateral stiffness and, due to their post-buckling behaviour, a not negligible contribution to the energy dissipation capacity of the structure.

In Tables 1-3 diagonal, beam and column sections resulting from the application of the proposed design procedure are summarised with reference to 4,6 and 8-storeys MRFCBF dual systems, respectively. The design ultimate displacement $\delta_{u}$ has been determined assuming that the maximum plastic rotation $\theta_{u}$ of beams is equal $0.04 \mathrm{rad}$, so that $\delta_{u}$ $=\theta_{u} \times h_{n s}$.

Therefore, ultimate displacements equal to $48 \mathrm{~cm}, 72 \mathrm{~cm}$ and $96 \mathrm{~cm}$ have been assumed in the design procedure for 4storeys, 6-storeys and 8-storeys structures, respectively. In addition, also the checks against the serviceability limit state have been conducted for the designed dual systems. According to Eurocode 8 provisions [16], damage limitation requirement is satisfied provided that the interstorey drifts, under a seismic action having a larger probability of occurrence than the design seismic action, are less than a given threshold value. In particular, for buildings having nonstructural elements fixed in a way so as not interfering with structural deformations, the following limitation has to be satisfied:

$\frac{d_{r}}{h} \cdot v \leq 0.010$

where $d_{r}$ is the design interstorey drift, i.e. the interstorey drift evaluated by a linear analyses with reference to the design seismic actions evaluated using the elastic spectra; $h$ is the interstorey height; $v$ is a reduction factor which takes into account the lower return period of the seismic action associated with the damage limitation state and it is dependent on the importance class of the building. For ordinary buildings a value of $v$ equal to 0.5 is suggested. In Table $\mathbf{4}$, the values of the constructional steel weight, corresponding to the design solutions given in Tables $\mathbf{1}$ to $\mathbf{3}$, and the interstorey drift values corresponding to the damage limitation state (DLS) are summarised for the three analysed MRF-CBF dual systems. From this table, it is possible to note that all the structures designed by means of the proposed design methodology fulfill also the drift limitation requirements, being the maximum interstorey drift always less than 0.010 (Eq. (35)). 
Table 1. Diagonal, Beam and Column Sections of the 4-Storeys MRF-CBF Dual System

\begin{tabular}{|c|c|c|c|c|c|}
\hline Storey & Diagonals & MRF Beams* & CBFs Beams** & Internal Columns & External Columns \\
\hline \hline 1 & CHS $127.0 \times 4.0$ & IPE 180 & IPE 240 & HEB 300 & HEB 160 \\
\hline 2 & CHS $114.3 \times 4.0$ & IPE 180 & IPE 240 & HEB 260 & HEB 140 \\
\hline 3 & CHS $114.3 \times 4.0$ & IPE 180 & IPE 240 & HEB 220 & HEB 140 \\
\hline 4 & CHS $114.3 \times 2.5$ & IPE 180 & IPE 240 & HEB 160 & HEB 140 \\
\hline
\end{tabular}

* beams of unbraced bays.

** beams of braced bay.

Table 2. Diagonal, Beam and Column Sections of the 6-Storeys MRF-CBF Dual System

\begin{tabular}{|c|c|c|c|c|c|}
\hline Storey & Diagonals & MRF Beams* & CBFs Beams** & Internal Columns & External Columns \\
\hline \hline 1 & CHS $139.7 \times 5.0$ & IPE 180 & IPE 240 & HEB 500 & HEB 220 \\
\hline 2 & CHS $133.0 \times 5.0$ & IPE 180 & IPE 240 & HEB 450 & HEB 200 \\
\hline 3 & CHS $127.0 \times 5.0$ & IPE 180 & IPE 240 & HEB 340 & HEB 180 \\
\hline 4 & CHS $114.3 \times 5.0$ & IPE 180 & IPE 240 & HEB 280 & HEB 240 \\
\hline 5 & CHS $114.3 \times 4.0$ & IPE 180 & IPE 240 & HEB 160 & HEB 140 \\
\hline 6 & CHS $114.3 \times 2.5$ & IPE 180 & IPE 240 & \\
\hline
\end{tabular}

* beams of unbraced bays.

** beams of braced bay.

Table 3. Diagonal, Beam and Column Sections of the 8-Storeys MRF-CBF Dual System

\begin{tabular}{|c|c|c|c|c|c|}
\hline Storey & Diagonals & MRF Beams* & CBFs Beams** & Internal Columns & External Columns \\
\hline \hline 1 & CHS $133.0 \times 6.0$ & IPE 180 & IPE 240 & HEB 650 & HEB 240 \\
\hline 2 & CHS $127.0 \times 6.0$ & IPE 180 & IPE 240 & HEB 600 & HEB 240 \\
\hline 3 & CHS $121.0 \times 6.0$ & IPE 180 & IPE 240 & HEB 500 & HEB 220 \\
\hline 4 & CHS $114.3 \times 6.0$ & IPE 180 & IPE 240 & HEB 340 & HEB 180 \\
\hline 5 & CHS $114.3 \times 5.0$ & IPE 180 & IPE 240 & HEB 300 & HEB 180 \\
\hline 6 & CHS $114.3 \times 4.0$ & IPE 180 & IPE 240 & HEB 260 & HEB 160 \\
\hline 7 & CHS $114.3 \times 3.0$ & IPE 180 & IPE 240 & HEB 160 & HEB 140 \\
\hline 8 & CHS $114.3 \times 2.5$ & IPE 180 & IPE 240 & \\
\hline
\end{tabular}

* beams of unbraced bays.

** beams of braced bay.

Finally, non-linear static push-over analyses have been carried out for the designed dual systems by means of SAP 2000 computer program. Structural members have been modelled by means of non linear elements. In particular, beams and columns have been modelled using beam-column elements with the possibility of developing plastic hinges at their ends (or in an intermediate position when the uniform vertical load $q_{j k}>4 M_{b, j k} / L_{j}^{2}$ as defined in Section 2). Diagonals have been modelled accounting for the possibility of yielding for the tensile members and for the occurrence of buckling for the compressed ones. Second order effects due to the vertical loads acting in the seismic load combination are also taken into account. In particular, as MRF-CBF dual systems are the only lateral resisting part for each one of the
Table 4. Constructional Steel Weights and Maximum Interstorey Drifts at the Damage Limitation State

\begin{tabular}{|c|c|c|}
\hline Structure & $\begin{array}{c}\text { Constructional Steel } \\
\text { Weight (tons) }\end{array}$ & $\begin{array}{c}\text { Maximum Interstorey Drift } \\
\text { (DLS) }\end{array}$ \\
\hline \hline MRF-CBF4 & 4.94 & 0.00620 \\
\hline MRF-CBF6 & 9.38 & 0.00625 \\
\hline MRF-CBF8 & 14.40 & 0.00705 \\
\hline
\end{tabular}

two main directions in which the seismic actions have to be considered, second order effects are also due to the vertical 
loads acting on the leaning part of the structure. In addition, for each step of the analysis, the member stability checks have been performed according to Eurocode 3 provisions [17].

In Figs. (5-7) the pushover curves (horizontal forces multiplier versus top sway displacement) obtained from the analyses are depicted for the three designed MRF-CBF dual systems. In addition, the global mechanism equilibrium curve, expressed by Eq. (1) with $\alpha=\alpha^{(g)}$ and $\gamma=\gamma^{(g)}$, is also given. The comparison between the linearized equilibrium curve and the softening branch resulting from the push-over analyses provides a first confirmation of the accuracy of the design methodology.

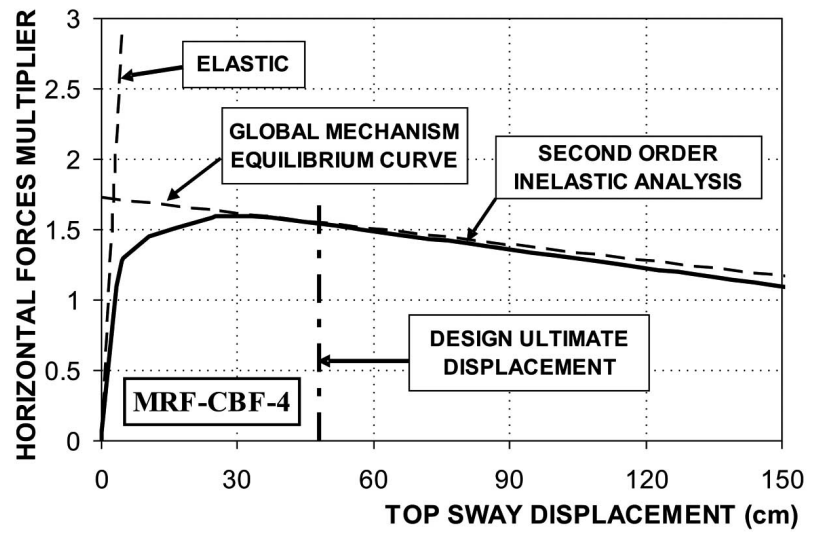

Fig. (5). Push over curve for the 4-storeys MRF-CBF dual system.

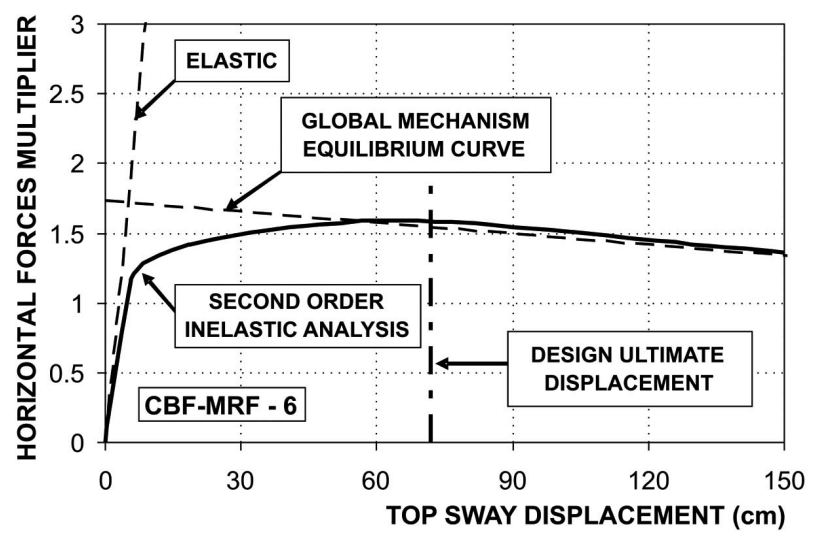

Fig. (6). Push over curve for the 6-storeys MRF-CBF dual system.

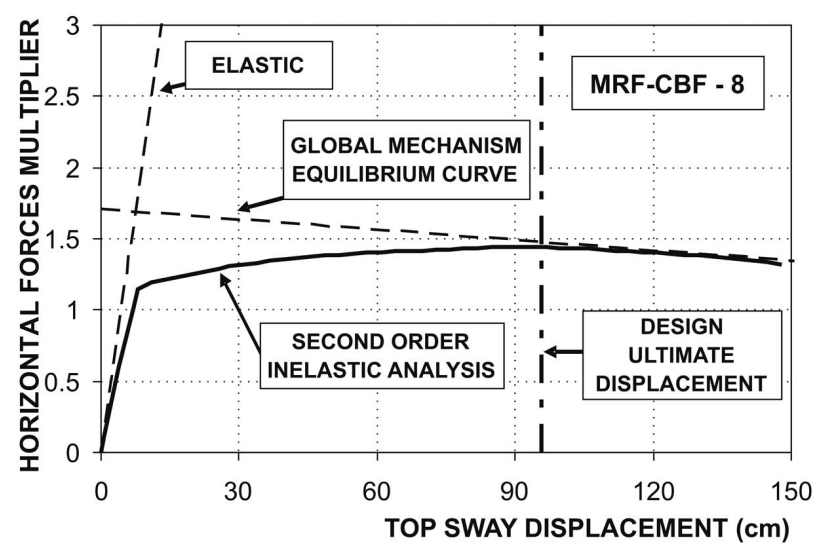

Fig. (7). Push over curve for the 8-storeys MRF-CBF dual system.
In addition, in Fig. (8) the actual pattern of yielding developed at the design ultimate displacement is depicted with reference to the three designed dual systems (aiming at a clear graphical representation, hinges located at 0.25 times the bracing element length denotes the yielding of tensile diagonals and the occurrence of buckling of the compressed ones). In Fig. (8), different colours are used aiming to the representation of the plastic hinges involvement with reference to the plastic rotation of beam ends and the axial elongation of tensile diagonals; finally, grey coloured hinges identify the occurrence of buckling for compressed diagonals.

It can be observed, in the same Figure, that all the tensile diagonals are yielded and all the compressed ones are buckled. The plastic hinges develop at beam ends and only at the base of the columns, confirming the fulfilment of the design goal, i.e. the failure mode control.

In conclusion, the results of these preliminary analyses have shown the accuracy of the proposed design methodology able to address the plastic deformations in dissipative members only, preventing the development of undesired failure mechanisms (i.e. soft and partial storey mechanisms). In addition, for the designed systems, also the damage limitation requirement, provided by Eurocode 8 provisions [16] (Eq. (35)), is satisfied. However, the proposed design procedure can be successfully applied even when more severe limitations to the interstorey drift are needed. For example, for buildings having non-structural elements of brittle materials attached to the structure, Eurocode 8 requires the maximum interstorey drift at the damage limitation state to be less than 0.005. In such case, none of the dimensioned MRF-CBFs dual systems is able to fulfill the damage limitation requirement. In order to design structures failing in a global mode, but also satisfying such damage limitation, an iterative design procedure can be applied. It consists in repeating the proposed design methodology for failure mode control by assuming increased sections of beams for unbraced bays (strategy 1) or increased diagonal sections (strategy 2). The iterative procedure will stop when the designed structure also satisfies the damage limitation requirement. In the first case (strategy 1), because of the increase in beam resistance (i.e. the increase in the internal work due to the beams), in order to guarantee the development of a global mechanism, stronger column sections are required, so that also the lateral stiffness increases. Obviously, by increasing beam and column sections, a considerable increase in constructional steel weight is also obtained. Conversely, the second strategy provides a negligible increase in constructional steel weight. In fact, by adopting diagonals with increased axial resistance, a strong increase of the structural lateral stiffness is gained, whereas an increase of minor importance of the column sections needed to guarantee the development of a global mechanism occurs.

The described iterative procedure has been applied with reference to the three analysed structures by assuming a threshold value of the interstorey drift at the damage limitation state equal to 0.005 . Diagonal, beam and column sections resulting from the design procedure are now summarised in Tables 5-7 with reference to the 4-storeys, 6-storeys and 8-storey buildings, respectively, and to the described strategies for drift control. 


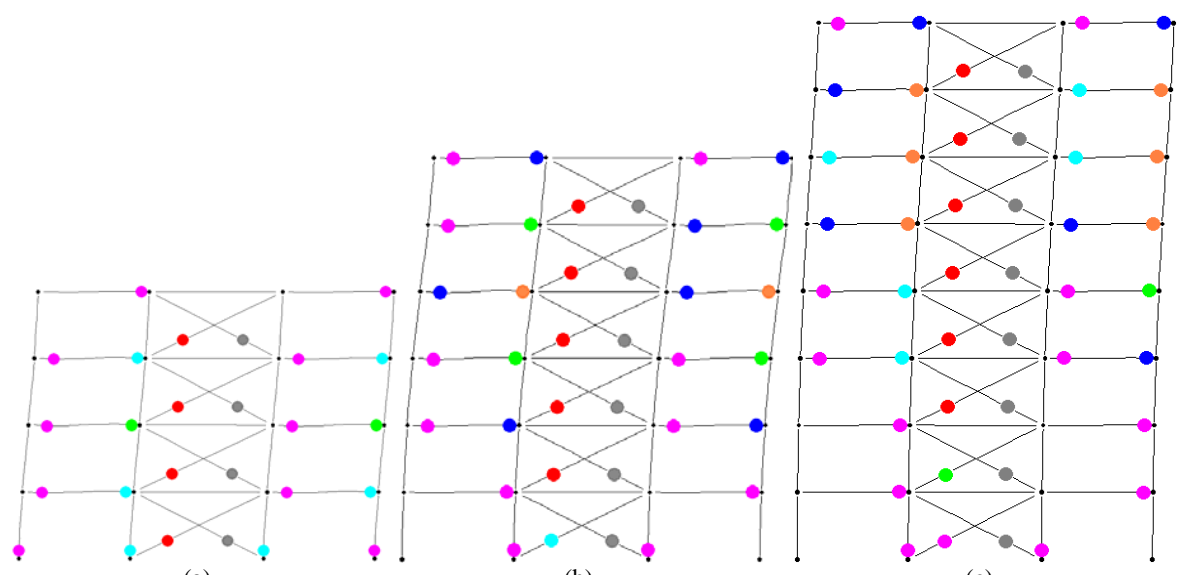

(a)

(b)

(c)

Fig. (8). Distribution of plastic hinges corresponding to the ultimate displacement for: a) 4-storeys, b) 6-storeys, c) 8-storeys MRF-CBF dual systems (for axial hinges in tension diagonals the plastic involvement refers to axial deformation $\delta$ instead of the rotation $\theta$ ).

Table 5. Diagonal, Beam and Column Sections of the 4-Storeys MRF-CBF Dual System Resulting from the Iterative Procedure (Strategy 1 and 2)

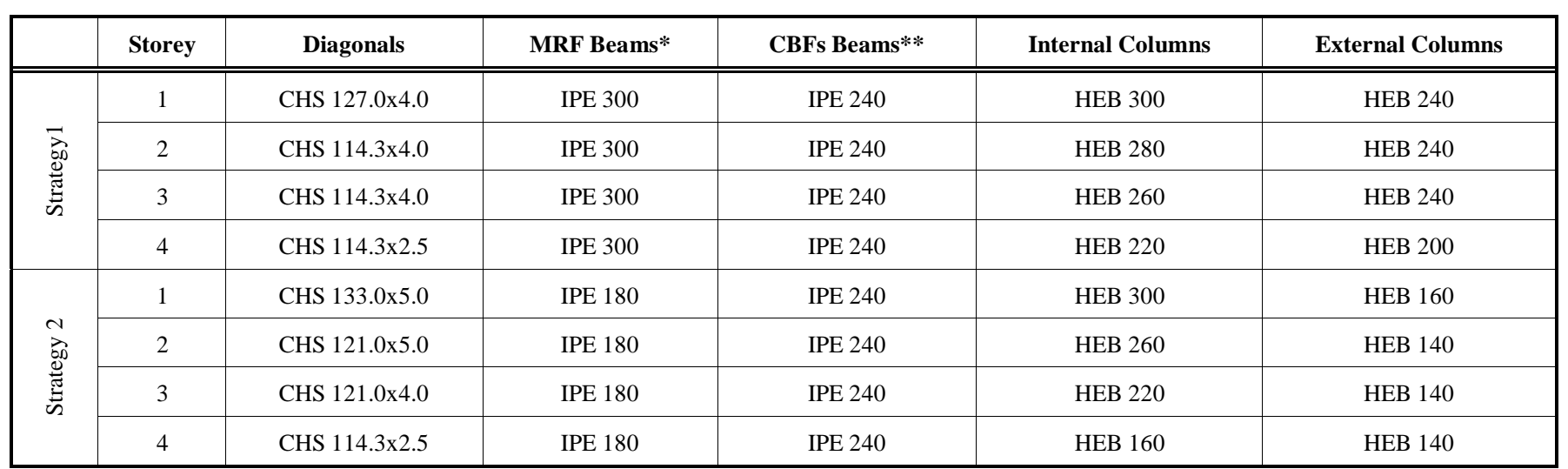

* beams of unbraced bays ** beams of braced bay.

Table 6. Diagonal, Beam and Column Sections of the 6-Storeys MRF-CBF Dual System Resulting from the Iterative Procedure (Strategy 1 and 2)

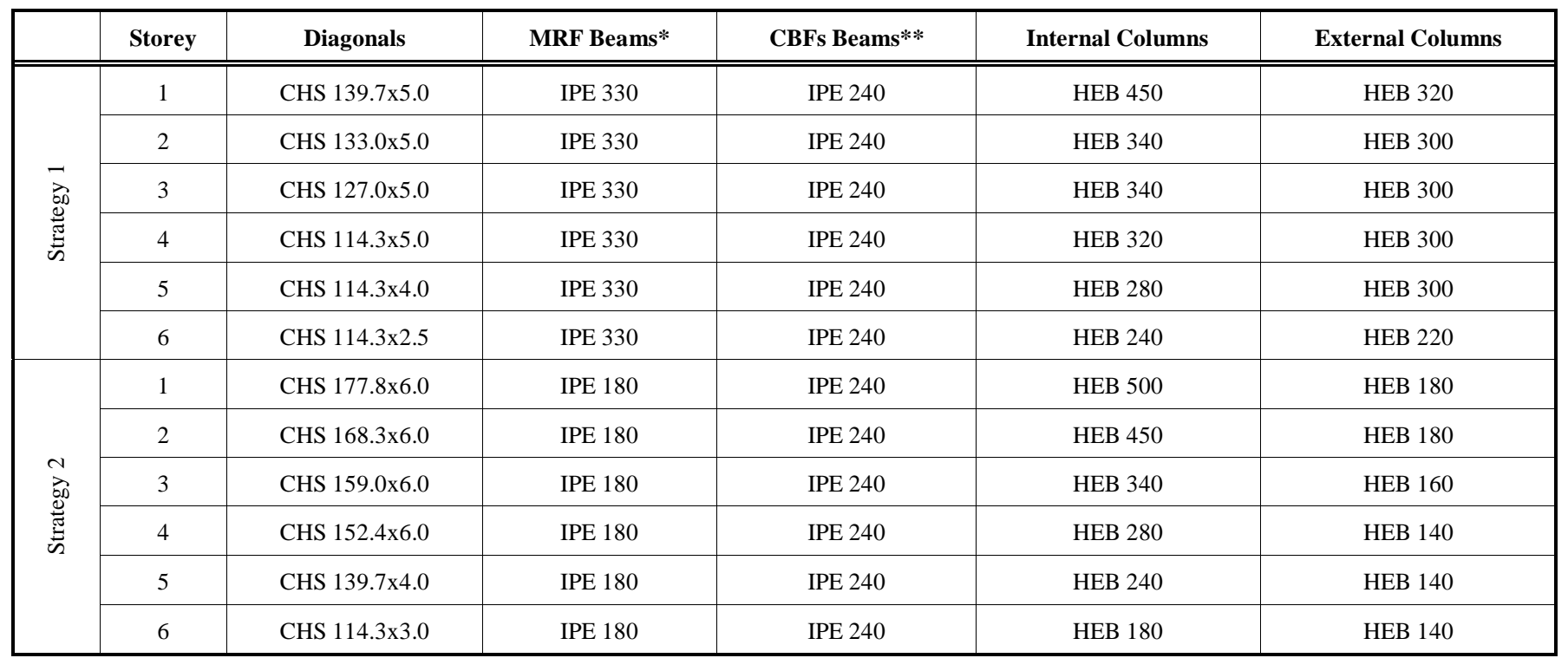

* beams of unbraced bays ** beams of braced bay. 
Table 7. Diagonal, Beam and Column Sections of the 8-Storeys MRF-CBF Dual System Resulting from the Iterative Procedure (Strategy 1 and 2)

\begin{tabular}{|c|c|c|c|c|c|c|}
\hline & Storey & Diagonals & MRF Beams* & CBFs Beams** & Internal Columns & External Columns \\
\hline \multirow{5}{*}{ 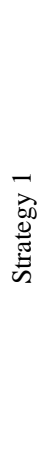 } & 3 & CHS $121.0 \times 6.0$ & IPE 360 & IPE 240 & HEB 400 & HEB 450 \\
\hline & 4 & CHS $114.3 \times 6.0$ & IPE 360 & IPE 240 & HEB 400 & HEB 450 \\
\hline & 6 & CHS $114.3 \times 4.0$ & IPE 360 & IPE 240 & HEB 320 & HEB 450 \\
\hline & 7 & CHS $114.3 \times 3.0$ & IPE 360 & IPE 240 & HEB 300 & HEB 340 \\
\hline & 8 & CHS $114.3 \times 2.5$ & IPE 360 & IPE 240 & HEB 260 & HEB 240 \\
\hline \multirow{6}{*}{ 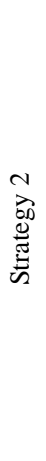 } & 1 & CHS 291.0x6.0 & IPE 180 & IPE 240 & HEB 700 & HEB 220 \\
\hline & 4 & CHS $177.8 \times 6.0$ & IPE 180 & IPE 240 & HEB 500 & HEB 180 \\
\hline & 5 & CHS $159.0 \times 6.0$ & IPE 180 & IPE 240 & HEB 400 & HEB 180 \\
\hline & 6 & CHS $139.7 \times 5.0$ & IPE 180 & IPE 240 & HEB 320 & HEB 180 \\
\hline & 7 & CHS $133.0 \times 4.0$ & IPE 180 & IPE 240 & HEB 260 & HEB 160 \\
\hline & 8 & CHS $114.3 \times 2.5$ & IPE 180 & IPE 240 & HEB 200 & HEB 140 \\
\hline
\end{tabular}

* beams of unbraced bays ** beams of braced bay.

In addition, in Table $\mathbf{8}$ the constructional steel weight and the maximum interstorey drifts at the damage limitation state are given. In the same table, the percentage variations of the constructional steel weight with respect to the initial solutions (Table 4) are also summarised.

As it can be observed the first strategy, consisting in the adoption of increased sections for beams of unbraced bays, provides a significant increase in constructional steel weight, ranging from $48 \%$ to $52 \%$ for the different number of storeys. Conversely, the second strategy, consisting in the adoption of diagonals with increased axial stiffness, provides a negligible percentage variation of constructional steel weight.

Finally, the inelastic behaviour of these structures has also been investigated by means of non-linear static push over analyses. For sake of synthesis, only the results con- cerning the 6-storeys dual system are reported. In Fig. (9) and (10) the pushover curves obtained from the analyses are depicted for the 6-storeys MRF-CBF dual systems designed to match the drift limitation equal to 0.005 by applying the iterative procedure with reference to strategy 1 and 2, respectively. Also in this case the global mechanism equilibrium curves show a very good agreement with the push over curves, confirming the accuracy of the design methodology. In addition, by comparing the push over curves depicted in Fig. (9) and (10) with that one in Fig. (6), regarding the initial solution for a drift limit equal to 0.010 , as pointed out in Fig. (11), it can be observed that the iterative procedure, implemented by means of both strategy 1 and 2 , provides an increase of the lateral stiffness (being the main goal of the iterative procedure aimed at the fulfilment of the damage limitation requirement), but also a significant increase of the lateral resistance of the MRF-CBF dual system.

Table 8. Constructional Steel Weight and Maximum Interstorey Drifts at the Damage Limitation State for Structures Resulting from the Iterative Procedure

\begin{tabular}{|c|c|c|c|c|c|c|}
\hline \multirow[b]{2}{*}{ Structure } & \multicolumn{3}{|c|}{ STRATEGY 1} & \multicolumn{3}{|c|}{ STRATEGY 2} \\
\hline & $\begin{array}{l}\text { Constructional steel } \\
\text { weight (tons) }\end{array}$ & $\begin{array}{l}\text { Percentage varia- } \\
\text { tion }\end{array}$ & $\begin{array}{l}\text { Interstorey drift } \\
\text { (DLS) }\end{array}$ & $\begin{array}{l}\text { Constructional steel } \\
\text { weight (tons) }\end{array}$ & $\begin{array}{l}\text { Percentage varia- } \\
\text { tion }\end{array}$ & $\begin{array}{l}\text { Interstorey drift } \\
\text { (DLS) }\end{array}$ \\
\hline MRF-CBF4 & 7.15 & $48 \%$ & 0.0050 & 4.95 & $2 \%$ & 0.0049 \\
\hline MRF-CBF6 & 13.62 & $45 \%$ & 0.0050 & 9.64 & $3 \%$ & 0.0049 \\
\hline
\end{tabular}




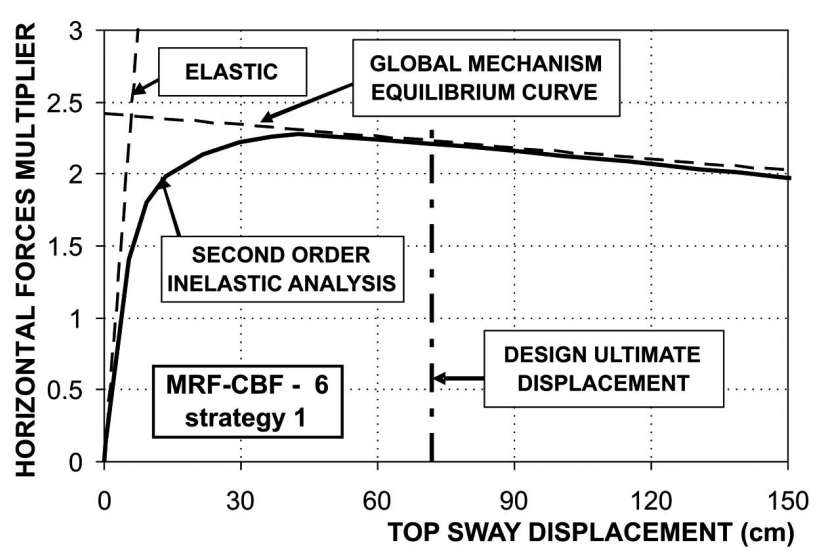

Fig. (9). Push over curve for the 6-storeys MRF-CBF dual system resulting from the iterative procedure (Strategy 1 ).

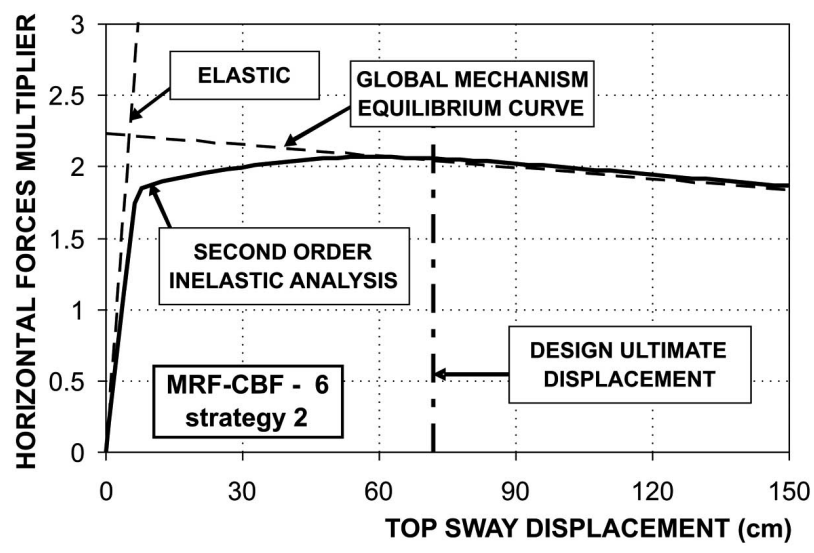

Fig. (10). Push over curve for the 6-storeys MRF-CBF dual system resulting from the iterative procedure (Strategy 2 ).

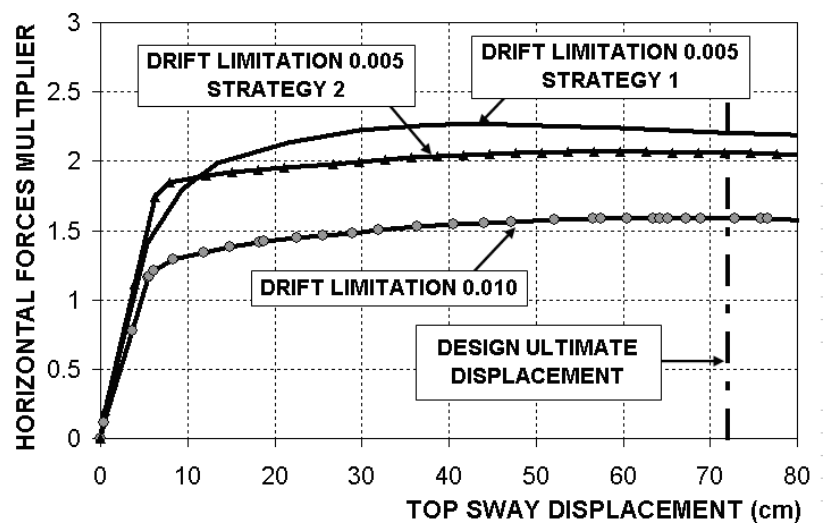

Fig. (11). Comparison between push over curves obtained by means of the different adopted strategies.

In addition, in Fig. (12) the actual pattern of yielding developed at the design ultimate displacement is depicted for the two 6-storeys structures designed by means of the procedure for drift and collapse mechanism control by using strategy 1 and 2 . In both cases, the analysis results confirm the fulfilment of the design goal, i.e. the failure mode control.

No results are available yet regarding the energy dissipation capacity of these systems and the amount of energy dis- sipated by beams and diagonals for structures designed by means of the two strategies. In fact, to this scope dynamic non linear analyses will be carried out in the forthcoming developments of this research activity. Nevertheless, by comparing Fig. (12a) and Fig. (12b), it can be observed that the structure designed by means of strategy 1 (i.e. by increasing the beam sections of unbraced bays) exhibits a major involvement of beams with respect to strategy 2 (i.e. by increasing the diagonal axial stiffness). Therefore, the second strategy allows, on one hand, to satisfy severe drift limitations with a negligible increase in constructional steel weight, but, on the other hand, provides a minor involvement of beams, as inelastic deformations mainly develop in bracing members. On the contrary, the first strategy provides a considerable increase in constructional steel weight, but a more uniform distribution of inelastic deformations.

\section{CONCLUSIONS}

In this paper, a design methodology aimed at the failure mode control, already successfully applied with reference to MRFs [1, 2], CBFs [3, 4] EBFs [5, 6] and KBFs [7], has been implemented for MRF-CBF dual systems. In addition, structures with different number of storeys (4, 6 and 8$)$ have been dimensioned according to the described design procedure. Non-linear static push-over analyses have been carried out in order to check the accuracy of the proposed design methodology. The results have pointed out the fulfilment of the design goal, showing the development of global mechanisms characterized by the yielding of tension diagonals, the buckling of compressed ones and by formation of plastic hinges at beam ends. Finally, the design issues concerning damage limitation have also been investigated for the designed structures with reference to Eurocode 8 provisions. The results have shown that the designed dual systems also satisfy the damage limitation requirements provided for buildings whose non-structural elements do not interfere with the structural deformation.

However, the proposed design methodology can be successfully applied even when more severe drift limitation requirements are provided. To this aim, an iterative procedure has been described consisting in repeating the design procedure, for failure mode control, by increasing beam sections of the unbraced bays, denoted as strategy 1 , or by increasing diagonal sections, denoted as strategy 2 , until the required drift limitation is satisfied. In this way, both the control of the failure mechanism and the fulfilment of the serviceability requirements can be reached. The obtained results, conducted by assuming a threshold interstorey drift value for the damage limitation state equal to 0.005 , have pointed out that strategy 2 provides the greatest saving in constructional steel weight; nevertheless inelastic deformations mainly develop in bracing members. On the contrary, strategy 1 provides a more uniform distribution of inelastic deformations in beams and diagonals, but provides a considerable increase in constructional steel weight.

Regarding the future developments of the presented research activity, non-linear dynamic analyses of MRF-CBF dual systems, designed to fail in global mode, will be carried out in order to investigate the pattern of yielding under seismic motion and the energy dissipation capacity provided by these structures. These analyses will provide further insight 


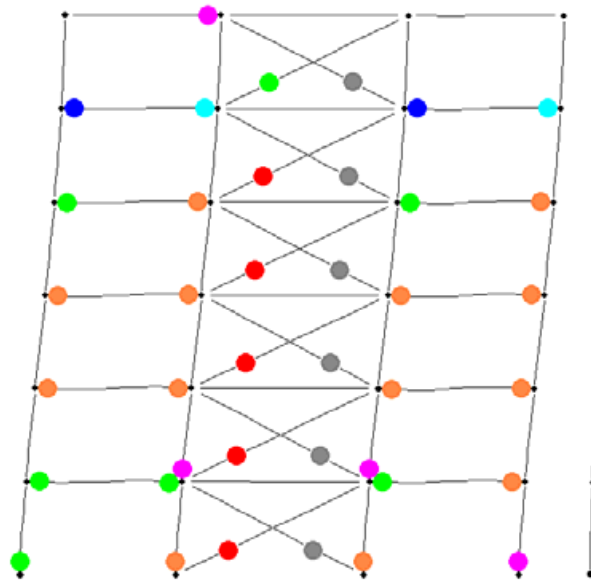

(a)

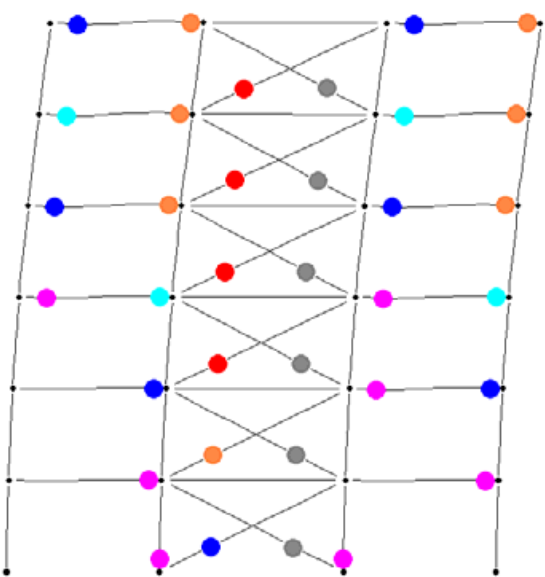

(b)

Fig. (12). Distribution of plastic hinges corresponding to the a displacement level less than the ultimate displacement for 6-storeys MRF-CBF dual systems resulting from the iterative procedure implemented by means of a) Strategy 1; b) Strategy 2 (for axial hinges in tension diagonals the plastic involvement refers to axial deformation $\delta$ instead of the rotation $\theta$ ).

regarding the best strategy to be applied to assure both failure mode control and damage limitation requirements.

\section{REFERENCES}

[1] F. M. Mazzolani, and V. Piluso, Theory and design of Seismic resistant Steel Frames, London: E \& FN spon, 1996.

[2] F. M. Mazzolani, and V. Piluso, "Plastic design of seismic resistant steel frames", Earthquake Engineering and Structural Dynamics, vol. 26, pp. 167-191, 1997.

[3] A. Longo, R. Montuori, and V. Piluso, "Failure mode control of Xbraced frames under seismic actions", Journal of Earthquake Engineering, vol. 12, pp. 728-759, 2008

[4] A. Longo, R. Montuori, and V. Piluso, "Plastic design of seismic resistant V-braced frames", Journal of Earthquake Engineering, vol. 12, pp. 1246-1266, 2008.

[5] L. Mastrandrea, and V. Piluso, "Plastic design of eccentrically braced frames, I: Moment-shear interaction", Journal of Constructional Steel Research, vol. 65, no. 3, 1007-1014, 2009.

[6] L. Mastrandrea, and V. Piluso, "Plastic design of eccentrically braced frames, II: Failure mode control", Journal of Constructional Steel Research, vol. 65, no. 3, 1015-1028, 2009.

[7] M. A. Conti, L. Mastrandrea, and V. Piluso, "Plastic design and seismic response of knee braced frames", Advanced Steel Construction, vol. 5, no. 3, pp. 343-366, 2009.

[8] F. M. Mazzolani, D. Georgescu, and A. Astaneh-Asl, "Remarks on behaviour of concentrically and eccentrically braced steel frames, STESSA 1994," In: 1st International Conference on Behaviour of Steel Structures in Seismic Areas, Timisoara: Romania, 1994.
[9] A. K. Jain, S. C. Goel, and R. D. Hanson, Hysteresis Behaviour of Bracing Members and Seismic Response of Braced Frames with Different Proportions, Report UMEE 78R3, Department of Civil Engineering, The University of Michigan, 1978.

[10] B. V. Fell, A. T. Myers, G. G. Deierlein, and A. M. Kanvinde, "Testing and simulation in steel braces," In: 8th U.S. National Conference on Earthquake Engineering, San Francisco: USA, 2006.

[11] D. Georgescu, C. Toma, and O. Gosa, "Post-critical behaviour of 'K' braced frames", Journal of Constructional Steel Research, vol. 21, pp. 115-113, 1991.

[12] R. Tremblay, "Inelastic seismic response of steel bracing members", Journal of Constructional Steel Research, vol. 58, pp. 665701, 2002.

[13] A. Longo, L. Mastrandrea, and V. Piluso, Design Approach for Failure Mode Control of MRF-CBF Dual Systems. EUROSTEEL 2008, Graz: Austria, 2008.

[14] M. T. Giugliano, A. Longo, L. Mastrandrea, R. Montuori, and V. Piluso, "Plastic design of MRF-CBF systems," In: ICASS '09 Sixth International Conference on Advances in Steel Structures, Hong Kong: China, 2009.

[15] CSI. SAP 2000: Integrated Finite Element Analysis and Design of Structures. Analysis Reference. Berkeley: Computers and Structures Inc., University of California; 1998.

[16] CEN. EN 1998-1-1-Eurocode 8-Design of Structures for Earthquake Resistance. Part 1: General Rules, Seismic Actions and Rules for Buildings. Comité Européen de Normalisation, 2004.

[17] CEN. EN 1993-1-1-Eurocode 3: Design of Steel Structures. Part 1: General Rules and Rules for Buildings. Comité Européen de Normalisation, 2005.

This is an open access article licensed under the terms of the Creative Commons Attribution Non-Commercial License (http://creativecommons.org/licenses/by-nc/3.0/) which permits unrestricted, non-commercial use, distribution and reproduction in any medium, provided the work is properly cited. 